\title{
Assessment of sleep problems with the Insomnia Severity Index (ISI) and the sleep item of the Patient Health Questionnaire (PHQ-9) in cancer patients
}

\author{
Thomas Schulte $^{1} \cdot$ Dirk Hofmeister $^{2} \cdot$ Anja Mehnert-Theuerkauf $^{2} \cdot$ Tim Hartung $^{2,3} \cdot$ Andreas Hinz $^{2}$ (I)
}

Received: 19 January 2021 / Accepted: 5 May 2021 / Published online: 29 May 2021

(C) The Author(s) 2021

\begin{abstract}
Objective The objectives of this study were to examine sleep problems in cancer patients, to test the psychometric properties of the Insomnia Sleep Index (ISI) in comparison with the sleep item of the Patient Health Questionnaire-9 (PHQ-9), and to analyze disrupting factors which might cause the sleep problems.

Methods A sample of 1026 mixed-site cancer patients in treatment at a German oncological rehabilitation clinic was examined.

Results The reliability of the ISI was very good (Cronbach's alpha $=0.92)$, and the results of the confirmatory factor analysis were acceptable. Females reported worse sleep quality (ISI mean: $13.7 \pm 6.6)$ than males $(10.7 \pm 6.4)$. Sleep problems as measured with the PHQ-9 sleep item were markedly higher than those in the general population (effect size $d=1.15$ ). Patients reported that, of the factors that disrupted their sleep, psychological factors (brooding, worries) were more relevant than symptom factors (pain, nocturnal urination, or restless legs).

Conclusions The ISI is effective in detecting sleep problems in cancer patients. Normative studies with the ISI would be helpful for assessing ISI mean scores. Sex differences should be taken into account when groups of patients are compared. The sleep item of the PHQ-9 can be used in epidemiological studies.
\end{abstract}

Keywords Cancer $\cdot$ Insomnia $\cdot$ Oncology $\cdot$ Psychometrics $\cdot$ Psycho-oncology $\cdot$ Sleep disturbances

\section{Introduction}

Sleep problems are frequent in cancer patients [1]; the prevalence of sleep disturbances has been found to range from 30 to $93 \%$ [2]. Sleep problems often do not disappear after cancer treatment [3], and they are associated with reduced quality of life [4, 5], depression [6], impaired concentration $[7,8]$, and even reduced survival rates $[9,10]$. In clinical practice, sleep problems often remain undetected and untreated despite the high prevalence $[11,12]$.

Andreas Hinz

andreas.hinz@medizin.uni-leipzig.de

1 Rehabilitation Clinic Bad Oexen, Bad Oeynhausen, Germany

2 Department of Medical Psychology and Medical Sociology, University of Leipzig, 04103 Leipzig, Germany

3 Jewish Hospital, Berlin, Germany
Several questionnaires have been developed for effectively measuring sleep quality [13]. One of these instruments is the 7-item Insomnia Severity Index (ISI) [14]. Its development was based on the diagnostic criteria for insomnia outlined in the fourth edition of the Diagnostic and Statistical Manual of Mental Disorders (DSM-IV) and the International Classification of Sleep Disorders (ICSD). Reliability estimates of the ISI in terms of Cronbach's alpha range from 0.74 to 0.92 [15]. While the ISI is generally used as a one-dimensional scale, several studies tested the factorial structure and obtained mixed results, with two-factorial $[15,16]$ and three-factorial $[17,18]$ solutions.

Age and sex differences in sleep quality have been examined by multiple studies conducted with both patient and general population samples. Many found that females report higher levels of sleep problems than males do, while no consistent age effects were observed [19-21]. Since cancer types and sex can be confounded, it is important to quantify sex differences when the impact of specific cancer types on sleep 
quality is to be examined. Therefore, one aim of this study was to also test age and sex differences.

In addition to questionnaires that only measure sleep quality, there are several for measuring quality of life (QoL), fatigue, or depression that include a sleep item. Examples of such instruments are: the Patient Health Questionnaire-9 (PHQ-9) [22], the General Health Questionnaire-12 (GHQ12) [23], and the European-Organization-For-Research-AndTreatment-Of-Cancer QoL questionnaire EORTC QLQ-C30 [24]. While it is presumable that the 7-item ISI is more effective in detecting sleep problems than are the single sleep items included in questionnaires such as the PHQ-9, this supposition must be empirically tested to establish whether or not that is in fact the case. For that reason, we compared the correlations of the ISI and the PHQ-9 sleep item with several other mental health and quality of life scales.

Oncologists often pay too little attention to sleep problems when treating cancer patients [25]. Moreover, even if they do use a suitable instrument for screening sleep quality and detect poor results, those findings do not reveal why the sleep disturbances occur. Therefore, we also investigated physical, mental, and environmental disruptive factors that patients report as causing them trouble sleeping.

In summary, the aims of this study were (a) to test psychometric properties of the ISI in comparison with the sleep item of the PHQ-9 in a large sample of cancer patients; (b) to analyze the effects of sex, age, and tumor type on sleep quality; and (c) to explore the role of disruptive factors which cause the sleep problems.

\section{Methods}

\section{Sample of patients}

This study was performed in a German oncologic rehabilitation clinic. In Germany, most cancer patients are offered the opportunity to spend some time, often 3 weeks, at a rehabilitation clinic to help restore their physical and social functioning after cancer treatment. Inclusion criteria for this study were age 18 years or older, the absence of cognitive impairment, and sufficient command of the German language. A total of 1350 patients were asked to take part in the study. Most of the patients were informed about the background and the objectives of the study in personal interviews at the beginning of the stay in the rehabilitation clinic. Of 1350 patients who were asked to participate, 1053 (78\%) were willing to do so. In most cases, the questionnaire was filled in several days after the beginning of the stay in the clinic. All study participants gave their consent to taking part in the study after having been informed of the data collection and data storage policy. The Ethics Committee of the Medical Faculty of the University of Leipzig approved the study.

\section{Instruments}

The ISI is a seven-item questionnaire for assessing sleep problems. The items cover (1) sleep onset, (2) sleep maintenance, (3) early morning awakening, (4) satisfaction level with current sleep pattern, (5) interference with daily living, (6) noticeability of impairment due to the sleep difficulty, and (7) level of distress caused by the sleep problem. Each item is rated on a 5-point Likert scale ranging from 0 to 4 , and is summed with the others to result in total scores ranging from 0 to 28 . The scores can be divided into categories as follows: no significant insomnia (0-7), subthreshold insomnia (8-14), moderate insomnia (15-21), and severe insomnia (22-28) [14, 26]. In this study, we used the German translation of the ISI [27].

The PHQ-9 is a screening instrument developed to measure depression [22]. For each of the nine items, the patients are asked to assess how much they were bothered by the given symptoms over the last 2 weeks. There are four answer options: not at all (0), several days (1), more than half of the days (2), and nearly every day (3). The sum score (range 0 to 27) indicates the degree of depression. One of the items pertains to sleep: "How often have you been bothered by trouble falling or staying asleep, or sleeping too much?" Normative values of the PHQ-9 are available [28]. The PHQ-2 is a shortened form of the PHQ-9 [29].

In addition to the ISI and the PHQ-9, we used the following questionnaires: the Generalized Anxiety Disorder screener GAD-2, measuring anxiety with two items [30, 31], the Adjustment Disorder New Module-8 (ADNM-8), a brief version of the ICD-11 adjustment disorder scale [32, 33], the Work Ability Score (WAS), a single-item measure for assessing work ability on a 0-10 scale [34], and an adapted version of the Diagnostic Criteria (DC) for measuring cancer-related fatigue. Here, we used the 11 criteria for measuring cancer-related fatigue developed by the Fatigue Coalition [35] and adopted a four-point Likert scale for each item [36]. Finally, we assessed QoL with the two-item general health/QoL scale of the EORTC QLQ-C30 [24].

To explore physical and mental factors that might have precipitated their sleep problems, the patients had to respond to 12 items representing potential causes. The factors were pain, nocturnal urination, brooding, worries, unsolved problems, sweat, hot flashes, cold feeling, restless legs, breathing difficulties, nightmares, and noise. The answer options for each of the factors ranged from 0 (not at all) to 3 (strongly). We calculated the mean scores of the answers and the frequencies of respondents who answered with 1 ("a bit") or greater.

\section{Statistical analysis}

The impact of sex and age on sleep quality was tested with two-factorial analyses of variance (ANOVAs), with the age categorized into five groups as shown in Table 1 . The impact 
of tumor category and time since diagnosis on sleep quality was tested with two-way ANOVAs including the covariate age group, separately for both sexes. Effect sized $d$ were calculated according to Cohen [37]. Cronbach's alpha coefficient was used to determine the reliability of the ISI. Linear associations between the sleep variables and other variables were calculated with Pearson correlation coefficients.

Confirmatory factor analyses (CFAs) were performed to evaluate the overall fit of the one-dimensional model. Fit indices were the $\mathrm{Chi}^{2}$ goodness-of-fit statistic, the comparative fit index (CFI), the Tucker-Lewis index (TLI), and the root mean square error of approximation (RMSEA). Hu and Bentler [38] advised that CFI and TLI values close to 0.95 are indicative of a good fit, and a RMSEA value of 0.08 or less indicates an acceptable fit of the model in relation to the degrees of freedom. CFA calculations were performed with MPlus version 6.1; all other statistics were performed with SPSS version 24.

\section{Results}

\section{Sample characteristics}

Of the 1053 patients who took part in the study, 27 had to be excluded because two or more of the seven ISI items had been omitted in their responses. If only one item was missing, it was replaced with the rounded mean of the remaining items. The final sample comprised 1026 patients, 433 males (42.2\%) and 593 females (57.8\%). Further details of the sample are given in Table 1.

The mean scores of the ISI items and the ISI sum score are presented in Table 2. All of the items contributed
Table 2 Item characteristics of the ISI

\begin{tabular}{llllll}
\hline No & Item & $M$ & $(\mathrm{SD})$ & $r_{\text {it }}$ & alpha del \\
\hline 1 & Problems falling asleep & 1.55 & $(1.21)$ & .67 & .91 \\
2 & Problems staying asleep & 2.18 & $(1.26)$ & .79 & .90 \\
3 & Early awakening & 1.62 & $(1.30)$ & .66 & .92 \\
4 & Dissatisfaction & 2.14 & $(1.06)$ & .85 & .90 \\
5 & Functional impairment & 1.28 & $(1.03)$ & .66 & .91 \\
6 & Noticeability & 1.75 & $(1.13)$ & .85 & .89 \\
7 & Distress & 1.86 & $(1.14)$ & .79 & .90 \\
Scale & & 12.39 & $(6.71)$ & & alpha $=.92$ \\
\hline
\end{tabular}

$M$, mean score (item range: $0-4$; scale range: $0-28$ ); $S D$, standard deviation; $r_{\mathrm{it}}$, part-whole-corrected item-test-correlation; alpha del., Cronbach's alpha if item deleted

substantially to the sum score, the part-whole-corrected item-test-correlations ranged from 0.66 to 0.85 , and Cronbach's alpha was 0.92 .

The CFA fit indices of the one-dimensional model were as follows: $\mathrm{Chi}^{2}(\mathrm{df})=152.376(14), \mathrm{CFI}=0.969$, $\mathrm{TLI}=0.954, \mathrm{RMSEA}=0.101$, and $\mathrm{SRMR}=0.026$.

\section{Correlations with other variables}

The correlations between the sleep variables and several other variables are given in Table 3. With the exception of the PHQ-9 (which also includes the PHQ-9 sleep item), all correlations of the ISI were slightly higher than those of the PHQ-9 sleep item.
Table 1 Sociodemographic and clinical characteristics of the sample

\begin{tabular}{|c|c|c|c|c|c|c|}
\hline & \multicolumn{2}{|c|}{ Total $(N=1026)$} & \multicolumn{2}{|c|}{ Males $(N=433)$} & \multicolumn{2}{|c|}{ Females $(N=593)$} \\
\hline & $N$ & $\%$ & $N$ & $\%$ & $N$ & $\%$ \\
\hline Age, mean (SD) in years & $M=58.1$ & $(15.5)$ & $M=63.0$ & $(14.2)$ & $M=54.5$ & $(15.4)$ \\
\hline \multicolumn{7}{|l|}{ Age category } \\
\hline $18-39$ years & 154 & 15.0 & 37 & 8.5 & 117 & 19.7 \\
\hline $40-49$ years & 121 & 11.8 & 23 & 5.3 & 98 & 16.5 \\
\hline $50-59$ years & 220 & 21.4 & 78 & 18.0 & 142 & 23.9 \\
\hline $60-69$ years & 269 & 26.2 & 134 & 30.9 & 135 & 22.8 \\
\hline$\geq 70$ years & 262 & 25.5 & 161 & 37.2 & 101 & 17.0 \\
\hline \multicolumn{7}{|l|}{ Diagnosis groups } \\
\hline Gastrointestinal & 191 & 18.7 & 113 & 26.1 & 79 & 13.3 \\
\hline Gynecologic, breast & 362 & 35.3 & 5 & 1.2 & 357 & 60.2 \\
\hline Urologic & 269 & 26.2 & 235 & 54.3 & 34 & 5.7 \\
\hline Hematooncologic & 126 & 12.3 & 59 & 13.6 & 67 & 11.3 \\
\hline Other & 77 & 7.5 & 21 & 4.8 & 56 & 9.4 \\
\hline \multicolumn{7}{|l|}{ Time since diagnosis } \\
\hline$\leq 6$ months & 604 & 58.9 & 293 & 67.7 & 311 & 52.4 \\
\hline$>6$ months & 422 & 41.1 & 140 & 32.3 & 282 & 47.6 \\
\hline
\end{tabular}


Table 3 Correlations between the sleep scales and other variables

\begin{tabular}{lll}
\hline & ISI & PHQ-9 sleep \\
\hline PHQ-9: depression & .59 & .65 \\
PHQ-2: depression & .45 & .42 \\
GAD-2: anxiety & .45 & .39 \\
ADNM-8: adjustment disorder & .57 & .50 \\
DC: fatigue & .61 & .58 \\
WAS: work ability & -.36 & -.34 \\
EORTC QoL: quality of life & -.37 & -.32 \\
ISI & - & .72 \\
\hline
\end{tabular}

All coefficients are statistically significant with $p<0.001$

\section{Sex and age differences in sleep quality}

Figures 1 shows sex and age differences in sleep problems measured with the ISI and the PHQ-9 sleep item. The overall mean scores (total sample) of the ISI and the sleep item of the PHQ-9 were $M=12.4 \pm 6.7$ and $M=1.65 \pm 1.02$, respectively. In all age groups, females reported more severe sleep problems than males did. The ISI mean scores were $13.7 \pm 6.6$ (females) and $10.7 \pm 6.4$ (males), the corresponding mean scores of the PHQ-9 sleep item were $1.83 \pm 1.00$ (females) and $1.41 \pm 1.00$ (males), resulting in sex effect sizes of $d=0.46$ (ISI) and $d=0.42$ (PHQ-9 sleep item). There were no linear age trends. The greatest degree of sleep problems was observed among 50 to 59-year-olds, while younger and older participants reported better sleep quality. Males and females showed roughly parallel curves, which is reflected by the very low and nonsignificant ANOVA interaction effects (see below).

The ANOVA results for testing sex and age effects on ISI sleep quality were as follows: sex: $F=32.4, p<0.001$; age group: $F=5.07, p<0.001$; sex $\times$ age group: $F=1.14$, $p=0.336$. The corresponding coefficients of the PHQ-9 sleep item were sex: $F=25.3, p<0.001$; age group: $F=5.49$, $p<0.001$; sex $\times$ age group: $F=1.42, p=0.214$.

Using the categories no, subthreshold, moderate, and severe sleep problems, the total sample was to be characterized as follows: no $(n=264 ; 25.7 \%)$; subthreshold $(n=362 ; 35.3 \%)$; moderate $(n=308 ; 30.0 \%)$, and severe $(n=92 ; 9.0 \%)$ sleep problems. For males, the percentages were as follows: no (32.3\%), subthreshold (40.0\%), moderate (23.8\%), severe $(3.9 \%)$, while for females the corresponding percentages were no (20.9\%), subthreshold (31.9\%), moderate $(34.6 \%)$, and severe $(12.6 \%)$.

\section{Impact of tumor type and time since diagnosis on sleep quality}

Table 4 presents mean scores for the ISI and the PHQ-9 sleep item, broken down by tumor type and time since diagnosis for both sexes. While for male patients there were no significant differences between the tumor-type groups, in the females' subsample, patients with hematooncologic cancer reported relatively few sleep problems. Time since diagnosis had no significant impact of sleep quality.

\section{Disruptive factors}

Mean scores of the items characterizing the disruptive factors are given in Table 5. The highest mean values $(M>1.0$ on the 0-3 scale) were found for nocturnal urination, brooding, worries, and unsolved problems. Table 5 also presents the proportions of participants who responded with scores of 1 ("a bit") or higher. Nocturnal urination and brooding were experienced by at least $75 \%$ of the patients, at least to a small degree. The highest correlations between the disruptive factors and the ISI was found for brooding $(r=0.58)$ and worrying ( $r=0.53$ ), while the correlation between nocturnal urination and ISI sleep quality $(r=0.26)$ was relatively low.

\section{Discussion}

The first aim of this investigation was to test the psychometric quality of the ISI. Cronbach's alpha (0.92) was very good. Yusufov et al. [15] compiled several studies with 12 alpha coefficients, ranging from 0.75 to 0.92 . That is, the
Fig. 1 ISI and PHQ-9 sleep item mean scores, broken down by gender and age

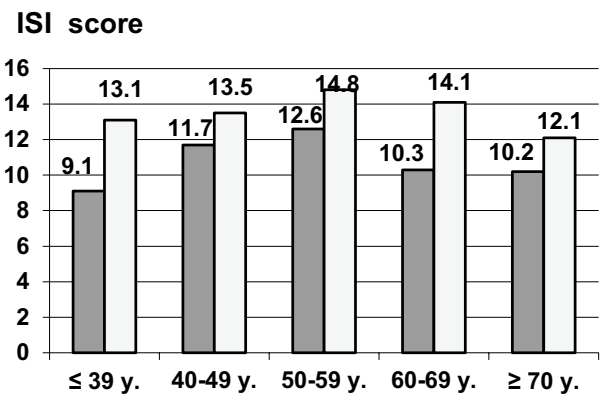

$\square$ Males

$\square$ Females

\section{PHQ-9 Sleep item}

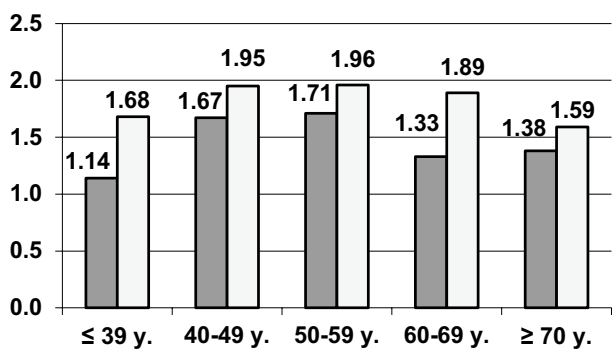

Males $\quad$ Females 
Table 4 Impact of clinical variables on sleep quality

\begin{tabular}{|c|c|c|c|c|c|c|c|c|}
\hline & \multicolumn{4}{|l|}{ ISI } & \multicolumn{4}{|c|}{ PHQ-9 sleep item } \\
\hline & \multicolumn{2}{|l|}{ Males } & \multicolumn{2}{|l|}{ Females } & \multicolumn{2}{|l|}{ Males } & \multicolumn{2}{|l|}{ Females } \\
\hline & $M$ & (SD) & $M$ & (SD) & $M$ & (SD) & $M$ & (SD) \\
\hline \multicolumn{9}{|l|}{ Diagnosis groups } \\
\hline Gastrointestinal & 11.0 & (6.5) & 13.9 & $(6.0)$ & 1.48 & $(0.97)$ & 1.90 & $(0.97)$ \\
\hline Gynecologic, breast & - & - & 13.5 & (6.6) & - & - & 1.86 & $(0.98)$ \\
\hline Urologic & 10.3 & (6.3) & 14.7 & $(5.9)$ & 1.34 & $(0.99)$ & 1.94 & $(0.95)$ \\
\hline Hematooncologic & 11.1 & $(6.4)$ & 11.8 & $(6.9)$ & 1.42 & $(1.05)$ & 1.48 & $(1.08)$ \\
\hline Other & 11.9 & (7.0) & 15.7 & (7.4) & 1.71 & (1.19) & 1.89 & $(1.01)$ \\
\hline ANOVA & $p=0.620$ & & $p=0.017$ & & $p=0.474$ & & $p=0.036$ & \\
\hline \multicolumn{9}{|l|}{ Time since diagnosis } \\
\hline$\leq 6$ months & 10.4 & (6.4) & 13.4 & $(6.6)$ & 1.41 & $(0.99)$ & 1.85 & $(1.00)$ \\
\hline$>6$ months & 11.9 & (6.4) & 13.9 & $(6.7)$ & 1.41 & $(1.02)$ & 1.81 & $(0.99)$ \\
\hline ANOVA & $p=0.335$ & & $p=0.372$ & & $p=0.990$ & & $p=0.646$ & \\
\hline
\end{tabular}

ANOVA: significance of the main effect (diagnosis group or time since diagnosis) in the ANOVA with age group as covariate

internal consistency in our study with cancer patients was at the upper end of the range. CFA results were also good. Three of the four criteria proposed by $\mathrm{Hu}$ and Bentler were met. We could also have calculated other CFA models. Splitting a scale into subscales generally improves the fit coefficients. Several studies found better fit indices for two- or three-factorial models $[15,16]$. However, even if the number of subscales ( 2 or 3 ) was identical in the different studies, the assignment of the items to the scales was heterogeneous. We believe that adding a new factor structure based on our data would not contribute to the assessment of the quality of the ISI. Whenever ISI sum scores are calculated and compared, it is only relevant how reliable this one-dimensional scale is.

Table 5 Disruptive factors

\begin{tabular}{llllll}
\hline No & Factor & $M$ & $(\mathrm{SD})$ & $\%>0$ & $r$ (factor, ISI) \\
\hline 1 & Pain & 0.69 & $(0.86)$ & $47 \%$ & .35 \\
2 & Nocturnal urination & 1.26 & $(0.94)$ & $77 \%$ & .26 \\
3 & Brooding & 1.25 & $(0.95)$ & $75 \%$ & .58 \\
4 & Worries & 1.11 & $(0.95)$ & $69 \%$ & .53 \\
5 & Unsolved problems & 1.02 & $(0.91)$ & $67 \%$ & .46 \\
6 & Sweat & 0.80 & $(0.95)$ & $50 \%$ & .35 \\
7 & Hot flashes & 0.75 & $(0.97)$ & $56 \%$ & .35 \\
8 & Cold feeling & 0.48 & $(0.77)$ & $34 \%$ & .23 \\
9 & Restless legs & 0.57 & $(0.85)$ & $37 \%$ & .31 \\
10 & Breathing difficulties & 0.23 & $(0.54)$ & $18 \%$ & .19 \\
11 & Nightmares & 0.46 & $(0.74)$ & $34 \%$ & .36 \\
12 & Noise & 0.42 & $(0.73)$ & $31 \%$ & .19 \\
\hline
\end{tabular}

$M$, mean score (range: $0-3$ ); $S D$, standard deviation; $\%>0$, proportion of respondents who answered at least with the category "a bit"
The sleep item of the PHQ-9 performed nearly as well as the ISI. The correlations between the PHQ-9 sleep item and the other scales (Table 5) were only slightly lower than the correlations of the ISI, and the age and gender effects in the ANOVAs were of nearly equal magnitude for the PHQ-9 sleep item and the ISI sum score. In addition, the sex and age effects and the differences in the tumor type showed similar patterns for the PHQ-9 sleep item and the ISI. If a study already includes the PHQ-9 for measuring depression, the PHQ-9 sleep item seems to be a roughly sufficient surrogate for a longer questionnaire such as the ISI. Unfortunately, our study did not include a gold standard which could be used to compare the sensitivity and specificity coefficients of both sleep instruments. In a study with Iranian cancer patients [2], the correlations between the ISI scores and the scores of two other sleep questionnaires, the Athens Insomnia Scale and the Pittsburgh Sleep Quality Index, were 0.64 and 0.58, respectively. In our study, the correlation between the ISI and the sleep item of the PHQ-9 was even somewhat higher $(r=0.72)$.

The magnitude of sleep problems in our sample was high. There are no normative studies for the ISI, but comparisons between our cancer patients and the general population can be performed using the PHQ-9 sleep item. The mean score obtained in the general population of the PHQ-9 sleep item was $M=0.63(\mathrm{SD}=0.75)$ [39], which is much lower than the score in our sample $(M=1.65, \mathrm{SD}=1.02)$. This represents a large difference (effect size $d=1.15$ ) and underlines the importance of sleep disturbances in patients with cancer.

ISI mean scores in samples which exclusively comprised patients with sleep disorders are even higher than the mean (12.4) of our cancer patients' sample, e.g., 16.4 in a Korean study [40] and 16.9 in an Italian study [17]. A study with 
German cancer patients reported a lower ISI mean score of 8.7 [3]. Surveys with non-clinical populations also yielded lower mean scores: 7.0 (employees of the police force and emergency response service corps) [41], 6.6 (students) [41], 6.7 (adolescents) [41], and 9.8 (general population aged 65 and above) [42]. Dieck et al. [43] investigated two groups, (a) people from the general population who were recruited to attend a sleep training group (ISI mean $=16.8)$ and $(b)$ a convenience sample of people who were offered the opportunity to have their sleep quality tested (ISI mean $=9.8$ ). All these samples of non-patients have certain peculiarities and are not representative of the general population. Normative studies of the ISI would be very helpful for assessing sleep problems among cancer patients.

Females reported having markedly more sleep problems than males in our study. This sex effect is a general phenomenon. Normative studies using different questionnaires confirm this sex difference $[19,20]$. However, the age trend was interesting in our sample. In the general population, Tibubos et al. [19] found an increase in sleep problems with increasing age, while Hinz et al. [20] did not. In our sample of cancer patients, we observed a non-linear trend with the most severe sleep problems occurring among 50- to 59-yearolds. Because people of this age are generally still participating in the work force, being ill with cancer impacts not only their health but their professional existence as well. Older people might consider their situation a little bit more relaxed since the occupational problems might disappear for the retired people or for those shortly before retirement. It has repeatedly been shown that sleep problems among unemployed/retired people are much higher than those who work full-time or half-time [19].

Several studies have analyzed the impact of sociodemographic and clinical factors, e.g., tumor type [16] or pain intensity [42], on sleep quality, but these studies did not investigate the specific disruptive factors to which the participants attribute their sleep problems. In our study, we investigated 12 of these factors. The main result was that, of the factors we included, mental factors played a greater role than physical factors. The highest correlations with sleep quality $(r>0.50)$ were found for brooding and worries, while the association between sleep problems and pain, sweat, and restless legs were markedly lower.

According to Spielman and Glovinsky [44, 45], there are three categories of factors involved in the development of sleep problems: predisposing factors, precipitating factors, and perpetuating factors. The disruptive factors included in our study mostly belong to the second category of precipitating factors; however, a clear assignment is not always possible. The most relevant factors of mental distress may follow from personality traits (category 1), or they may be caused by disease and treatment (category 2). The factors that proved to be most relevant in our study (brooding, worries) in terms of correlations with sleep problems may be caused by the disease (precipitating factors) or by personality traits (predisposing factors).

The comparison of the factors analyzed in this study shows that the mental factors are at least as relevant as the physical ones. Helping patients brood and worry less might be more effective in solving sleep problems than only reducing physical symptoms. Treatment programs for regaining good sleep should consider the importance of the role mental factors play. Cognitive-behavioral therapy for insomnia (CBT-I) has demonstrated its effectiveness in cancer patients and cancer survivors [46, 47].

Some limitations of the study should be mentioned. We assessed the degree of patient' subjectively experienced sleep problems and did not examine objective criteria of sleep quality or diagnoses of insomnia based on semi-structured interviews. Subjective and objective measurement methods can differ substantially [48, 49]. The sample of cancer patients who were all receiving treatment in a rehabilitation clinic is not totally representative of cancer patients in general. Those cancer patients who do not perceive severe physical or mental problems might be underrepresented in the rehabilitation clinic. However, a study which compared the QoL of hospitalized cancer inpatients, patients in treatment at a rehabilitation clinic, and cancer outpatients did not detect significant differences between those groups [50]. The PHQ-9 is only one of several questionnaires which contain a single sleep item; we cannot generalize that single-item scales are generally roughly as effective in detecting sleep problems as the seven-item ISI. In our study, we analyzed several disruptive factors, which, however, do not belong to a validated questionnaire, and the reliability and validity of these variables is unknown. In addition, even statistically significant associations between these factors and the ISI scores cannot be interpreted in a causal way: worries may result in sleep problems and vice versa.

\section{Conclusion}

The results of the study underline the importance of sleep problems experienced by cancer patients. The ISI proved to be a reliable instrument for measuring the subjectively perceived sleep quality, the instrument can be recommended for clinicians and researchers. Though the sleep item of the PHQ-9 also performed relatively well in detecting sleep problems, we do not recommend to use such a single-item measure in clinical routine instead of a validated questionnaire such as the ISI. This study also included disruptive factors and found that mental factors played a greater role than physical factors for explaining sleep disturbances. 
In conclusion, the ISI proved to be a reliable instrument for measuring sleep quality in cancer patients. Comparisons between groups with different types of cancer should always take into account that sex differences might contribute to the differences in the results. Normative studies with the ISI, derived from representatively selected people of the general population, would be very useful for interpreting the results of the patients' responses.

Authors' contributions Conceptualization: Thomas Schulte, Andreas Hinz and Anja Mehnert-Theuerkauf; methodology and data collection: Thomas Schulte; statistical analysis: Dirk Hofmeister, Tim Hartung and Andreas Hinz; writing original draft: Andreas Hinz; writing review and editing: all authors; funding acquisition: Andreas Hinz; supervision: Anja Mehnert-Theuerkauf.

Funding Open Access funding enabled and organized by Projekt DEAL. The study was funded by the Deutsche Krebshilfe, grant number 70112267.

Data availability The data that support the findings of this study are available from the corresponding author upon reasonable request.

Code availability We used the statistics software SPSS version 24 and MPlus version 6.1.

\section{Declarations}

Ethics approval The study was approved by the Ethics Committee of the Medical Faculty of the University of Leipzig.

Consent to participate Informed consent was obtained from all individual participants included in the study.

Conflict of interest The authors declare that they have no conflict of interest.

Open Access This article is licensed under a Creative Commons Attribution 4.0 International License, which permits use, sharing, adaptation, distribution and reproduction in any medium or format, as long as you give appropriate credit to the original author(s) and the source, provide a link to the Creative Commons licence, and indicate if changes were made. The images or other third party material in this article are included in the article's Creative Commons licence, unless indicated otherwise in a credit line to the material. If material is not included in the article's Creative Commons licence and your intended use is not permitted by statutory regulation or exceeds the permitted use, you will need to obtain permission directly from the copyright holder. To view a copy of this licence, visit http://creativecommons.org/licenses/by/4.0/.

\section{References}

1. Otte JL, Carpenter JS, Manchanda S, Rand KL, Skaar TC, Weaver M, Chernyak Y, Zhong X, Igega C, Landis C (2015) Systematic review of sleep disorders in cancer patients: can the prevalence of sleep disorders be ascertained? Cancer Med 4:183-200
2. Lin C-Y, Cheng ASK, Nejati B, Imani V, Ulander M, Browall M, Griffiths MD, Broström A, Pakpour AH (2020) A thorough psychometric comparison between Athens Insomnia Scale and Insomnia Severity Index among patients with advanced cancer. J Sleep Res 29:e12891

3. Schieber K, Niecke A, Geiser F, Erim Y, Bergelt C, Büttner-Teleaga A, Maatouk I, Stein B, Teufel M, Wickert M, Wuensch A, Weis J (2019) The course of cancer-related insomnia: don't expect it to disappear after cancer treatment. Sleep Med 58:107-113

4. Liu L, Fiorentino L, Rissling M, Natarajan L, Parker BA, Dimsdale JE, Mills PJ, Sadler GR, Ancoli-Israel S (2013) Decreased health-related quality of life in women with breast cancer is associated with poor sleep. Behav Sleep Med 11:189-206

5. Chen M-L, Yu C-T, Yang C-H (2008) Sleep disturbances and quality of life in lung cancer patients undergoing chemotherapy. Lung Cancer 62:391-400

6. Hofmeister D, Schulte T, Hinz A (2020) Sleep problems in cancer patients: a comparison between the Jenkins Sleep Scale and the single-item sleep scale of the EORTC QLQ-C30. Sleep Med 71:59-65

7. Weinger MB, Ancoli-Israel S (2002) Sleep deprivation and clinical performance. JAMA 287:955-957

8. Henneghan AM, Carter P, Stuifbergan A, Parmelee B, Kesler S (2018) Relationships between self-reported sleep quality components and cognitive functioning in breast cancer survivors up to 10 years following chemotherapy. Psychooncology 27:1937-1943

9. Phipps AI, Bhatti P, Neuhouser ML, Chen C, Crane TE, Kroenke $\mathrm{CH}$, Ochs-Balcom H, Rissling M, Snively BM, Stefanick ML, Treggiari MM, Watson NF (2016) Pre-diagnostic sleep duration and sleep quality in relation to subsequent cancer survival. J Clin Sleep Med 12:495-503

10. Gottfried T, Kamer I, Salant I, Urban D, Lawrence YR, Onn A, Bar J (2020) Self-reported sleep quality as prognostic for survival in lung cancer patients. Cancer Manage Res 12:313-321

11. Zhou ES, Partridge AH, Syrjala KL, Michaud AL, Recklitis CJ (2017) Evaluation and treatment of insomnia in adult cancer survivorship programs. J Cancer Surviv 11:74-79

12. Kwak A, Jacobs J, Haggett D, Jimenez R, Peppercorn J (2020) Evaluation and management of insomnia in women with breast cancer. Breast Cancer Res Treat 181:269-277

13. Chen D, Yin Z, Fang B (2018) Measurements and status of sleep quality in patients with cancers. Support Care Cancer 26:405-414

14. Morin CM, Belleville G, Bélanger L, Ivers H (2011) The Insomnia Severity Index: psychometric indicators to detect insomnia cases and evaluate treatment response. Sleep 34:601-608

15. Yusufov M, Zhou ES, Recklitis CJ (2019) Psychometric properties of the Insomnia Severity Index in cancer survivors. Psychooncology 28:540-546

16. Savard M-H, Savard J, Simard S, Ivers H (2005) Empirical validation of the Insomnia Severity Index in cancer patients. Psychooncology 14:429-441

17. Castronovo V, Galbiati A, Marelli S, Brombin C, Cugnata F, Giarolli L, Anelli MM, Rinaldi F, Ferini-Strambi L (2016) Validation study of the Italian version of the Insomnia Severity Index (ISI). Neurol Sci 37:1517-1524

18. Chen P-Y, Yang C-M, Morin CM (2015) Validating the crosscultural factor structure and invariance property of the Insomnia Severity Index: evidence based on ordinal EFA and CFA. Sleep Med 16:598-603

19. Tibubos AN, Zenger M, Schmalbach B, Beutel ME, Brähler E (2020) Measurement invariance, validation and normative data of the Jenkins Sleep Scale-4 (JSS-4) in the German general population across the life span. J Psychosom Res 130:109933

20. Hinz A, Glaesmer H, Brähler E, Löffler M, Engel C, Enzenbach C, Hegerl U, Sander C (2017) Sleep quality in the general population: psychometric properties of the Pittsburgh Sleep Quality Index, 
derived from a German community sample of 9284 people. Sleep Med 30:57-63

21. Santoso AMM, Jansen F, Lissenberg-Witte BI, Baatenburg de Jong RJ, Langendijk JA, Leemans CR, Smit JH, Takes RP, Terhaard CHJ, van Straten A, Verdonck-de Leeuw IM (2021) Poor sleep quality among newly diagnosed head and neck cancer patients: prevalence and associated factors. Support Care Cancer 29:1035-1045

22. Kroenke K, Spitzer RL, Williams JBW (2001) The PHQ-9 validity of a brief depression severity measure. J Gen Intern Med 16:606-613

23. Romppel M, Braehler E, Roth M, Glaesmer H (2013) What is the General Health Questionnaire-12 assessing? Dimensionality and psychometric properties of the General Health Questionnaire-12 in a large scale German population sample. Compr Psychiatry 54:406-413

24. Aaronson NK, Ahmedzai S, Bergman B, Bullinger M, Cull A, Duez NJ, Filiberti A, Flechtner H, Fleishman SB, Dehaes JCJM, Kaasa S, Klee M, Osoba D, Razavi D, Rofe PB, Schraub S, Sneeuw K, Sullivan M, Takeda F (1993) The European-Organization-For-Research-And-Treatment-Of-Cancer QLQ-C30 - a quality-of-life instrument for use in international clinical trials in oncology. J Natl Cancer Inst 85:365-376

25. Mercadante S, Adile C, Ferrera P, Masedu F, Valenti M, Aielli F (2017) Sleep disturbances in advanced cancer patients admitted to a supportive/palliative care unit. Support Care Cancer 25:1301-1306

26. Bastien CH, Vallieres A, Morin CM (2001) Validation of the Insomnia Severity Index as an outcome measure for insomnia research. Sleep Med 2:297-307

27. Gerber LH, Stout N, McGarvey C, Soballe P, Shieh CY, Diao GQ, Springer BA, Pfalzer LA (2011) Factors predicting clinically significant fatigue in women following treatment for primary breast cancer. Supp Care Cancer 19:1581-1591

28. Kocalevent RD, Hinz A, Brahler E (2013) Standardization of the depression screener patient health questionnaire (PHQ-9) in the general population. Gen Hosp Psychiatry 35:551-555

29. Löwe B, Kroenke K, Grafe K (2005) Detecting and monitoring depression with a two-item questionnaire (PHQ-2). J Psychosom Res 58:163-171

30. Löwe B, Wahl I, Rose M, Spitzer C, Glaesmer H, Wingenfeld K, Schneider A, Brähler E (2010) A 4-item measure of depression and anxiety: validation and standardization of the Patient Health Questionnaire-4 (PHQ-4) in the general population. J Affect Disord 122:86-95

31. Hinz A, Klein AM, Brähler E, Glaesmer H, Luck T, Riedel-Heller SG, Wirkner K, Hilbert A (2017) Psychometric evaluation of the Generalized Anxiety Disorder Screener GAD-7, based on a large German general population sample. J Affect Disord 210:338-344

32. Kazlauskas E, Gegieckaite G, Eimontas J, Zelviene P, Maercker A (2018) A brief measure of the International Classification of Diseases-11 adjustment disorder: investigation of psychometric properties in an adult help-seeking sample. Psychopathology 51:10-15

33. Zelviene P, Kazlauskas E, Eimontas J, Maercker A (2017) Adjustment disorder: empirical study of a new diagnostic concept for ICD-11 in the general population in Lithuania. Eur Psychiatry 40:20-25

34. El Fassi M, Bocquet V, Majery N, Lair ML, Couffignal S, Mairiaux P (2013) Work ability assessment in a worker population: comparison and determinants of Work Ability Index and Work Ability score. BMC Public Health 13:305

35. Cella D, Davis K, Breitbart W, Curt G (2001) Cancer-related fatigue: prevalence of proposed diagnostic criteria in a United States sample of cancer survivors. J Clin Oncol 19:3385-3391
36. Kuhnt S, Friedrich M, Schulte T, Cella D, Hinz A (2019) Screening properties of the diagnostic criteria for cancer-related fatigue. Oncol Res Treat 42:440-445

37. Cohen J (1988) Statistical power analysis for the behavioral sciences. Hillsdale, NJ, Erlbaum, 1988, vol 2.

38. Hu LT, Bentler PM (1999) Cutoff criteria for fit indexes in covariance structure analysis: conventional criteria versus new alternatives. Struct Equat Modeling 6:1-55

39. Hinz A, Mehnert A, Kocalevent R-D, Brähler E, Forkmann T, Singer S, Schulte T (2016) Assessment of depression severity with the PHQ-9 in cancer patients and in the general population. BMC Psychiatry 16:22

40. Cho YW, Song ML, Morin CM (2014) Validation of a Korean version of the insomnia severity index. J Clin Neurol 10:210-215

41. Gerber M, Lang C, Lemola S, Colledge F, Kalak N, HolsboerTrachsler E, Pühse U, Brand S (2016) Validation of the German version of the insomnia severity index in adolescents, young adults and adult workers: results from three cross-sectional studies. BMC Psychiatry 16:174

42. Dragioti E, Levin L-Å, Bernfort L, Larsson B, Gerdle B (2017) Insomnia severity and its relationship with demographics, pain features, anxiety, and depression in older adults with and without pain: cross-sectional population-based results from the PainS65+ cohort. Ann Gen Psychiatry 16:15

43. Dieck A, Morin CM, Backhaus J (2018) A German version of the Insomnia Severity Index. Somnologie 22:27-35

44. Spielman AJ, Glovinsky P (1991) Case studies in insomnia. In: Hauri PJ (ed) The varied nature of insomnia. Plenum Press, New York, pp 1-15

45. Savard J, Savard M-H (2013) Insomnia and cancer. Sleep Med Clin 8:373-387

46. Howell D, Oliver TK, Keller-Olaman S, Davidson J, Garland S, Samuels C, Savard J, Harris C, Aubin M, Olson K, Sussman J, Macfarlane J, Taylor C (2013) A Pan-Canadian practice guideline: prevention, screening, assessment, and treatment of sleep disturbances in adults with cancer. Support Care Cancer 21:2695-2706

47. Johnson JA, Rash JA, Campbell TS, Savard J, Gehrman PR, Perlis M, Carlson LE, Garland SN (2016) A systematic review and meta-analysis of randomized controlled trials of cognitive behavior therapy for insomnia (CBT-I) in cancer survivors. Sleep Med Rev 27:20-28

48. Kreutz C, Müller J, Schmidt ME, Steindorf K (2021) Comparison of subjectively and objectively assessed sleep problems in breast cancer patients starting neoadjuvant chemotherapy. Support Care Cancer 29:1015-1023

49. Jakobsen G, Engstrøm M, Thronæs M, Løhre ET, Kaasa S, Fayers P, Hjermstad MJ, Klepstad P (2021) Sleep quality in hospitalized patients with advanced cancer: an observational study using self-reports of sleep and actigraphy. Support Care Cancer 28:2015-2023

50. Hinz A, Weis J, Faller H, Brähler E, Härter M, Keller M, Schulz H, Wegscheider K, Koch U, Geue K, Götze H, Mehnert A (2018) Quality of life in cancer patients-a comparison of inpatient, outpatient, and rehabilitation settings. Support Care Cancer 26:3533-3541

Publisher's note Springer Nature remains neutral with regard to jurisdictional claims in published maps and institutional affiliations. 